\title{
Influence of the specimen production and preparation on the compressive strength and the fatigue resistance of HPC and UHPC
}

\author{
Marco Basaldella $(\mathbb{D} \cdot$ Nadja Oneschkow $\cdot$ Ludger Lohaus
}

Received: 14 September 2020/ Accepted: 27 March 2021 / Published online: 16 April 2021

(C) The Author(s) 2021

\begin{abstract}
The results of tests under monotonically increasing load and cyclic compression load are often analysed by means of probabilistic methods. Although there is a considerable scattering in the results, especially in the number of cycles to failure, the cause of these cannot be completely explained. The imperfections of the specimens tested are among the causes of this scattering mentioned in the literature. Based on a round robin test the influence of HPC and UHPC production and specimen preparation techniques on the mean values of the compressive strengths, number of cycles to failure and data scattering have been evaluated. The main findings of the study are that the production techniques have an influence on the compressive strength, however, do not affect the mean number of cycles to failure. Moreover, the accurate preparation of the specimens has a positive influence on the compressive strength and the scattering of the results of both compression and cyclic load tests. The mean number of cycles to failure of HPC specimens is not influenced by the preparation techniques, whereas the polishing technique may have a positive influence on the mean number of cycles to failure of UHPC specimens.
\end{abstract}

M. Basaldella $(\square) \cdot$ N. Oneschkow $\cdot$ L. Lohaus Institute of Building Materials Science, Leibniz University Hannover, Appelstraße 9A, 30167 Hannover, Germany

e-mail: m.basaldella@baustoff.uni-hannover.de
Keywords High-performance concrete $\cdot$ Ultra-high performance concrete Compressive strength .

Fatigue $\cdot$ Number of cycles to failure $\cdot$ Data scattering

\section{Introduction}

Fatigue stress is a frequently repeated stress whose maximum stress level is smaller than the strength of the material under monotonically increasing stress [1]. Typical for fatigue stresses is that they can lead to failure of the material although the strength of the material is not reached. The "fatigue strength" of concrete is generally defined as the maximum stress that can be withstood for a given number of load cycles [2-4]. In general, the fatigue verification for concrete plays a decisive role for slender structures of high- and ultra-high performance concrete with optimised section design and for structures subject to high vibration loads. Some examples are bridge girders, onshore and offshore installations, which are affected by time variant loads such as heavy traffic, wind and waves at the same time [5].

The mechanism of fatigue failure of concrete has been studied for a long time [6-8] during which the main focus was on the study of the number of cycles to failure to characterise the point of failure of concrete. Only recently has research begun to focus on the causes of data scattering [9], on describing the damage 
caused by cyclical loading [10-14]. Although there is still a considerable demand for research, the general context is known [15-20].

Fatigue tests exhibit a large scattering of results [20] and are influenced by other factors, such as the load frequency [14], environmental conditions [21-24] and specimen dimensions [25]. A further influence is the quality of the specimens tested both in terms of the geometry and concrete produced, which are generally assumed to be uniform and homogeneous, respectively.

Probabilistic procedures are often used on experimental test results to assess the fatigue resistance [26]. A typical way to present the results are the S-N (stress level-number of cycles to failure) curves called Wöhler diagrams, in which the ordinate represents the maximum cyclic stress level, while the abscissa describes the number of cycles at failure on a logarithmic scale. It is possible to find the "best fit" line that optimally describes the empirical results and the confidence intervals related by means of linear regression techniques. Taking into account the scattering and statistical distribution of the empirical data, S-N-P (stress level-number of cycles to failureprobability of failure) curves are obtained in which the probability of failure is introduced and the reliability of the material can be evaluated [9, 27-29]. Thus, the study of the influences on data scattering is an important aspect in establishing the material reliability, especially when analyses are conducted with data collected from the literature where the conditions for performing experimental tests often differ from each other. A large scattering of results was observed in [30] because the nature of each individual specimen used, such as the quality of the load surfaces and the alignment in the test machine, had a considerable influence. The inhomogeneous nature of the concrete itself, partially influenced by production techniques [31], is also considered to be part of the cause of the scattering of results.

Although the scattering of empirical fatigue results is examined from a statistical point of view, there is no research in the literature that investigates the influence of specimen production and preparation on the number of cycles to failure.

The Institute of Building Material Science of Leibniz University in Hannover is the initiator and co-ordinator of the Priority Programme SPP 2020 "Cyclic deterioration of High-Performance Concrete in an experimental virtual lab", which is financed by the German Research Foundation and aims to better understand and describe the damage processes in concrete. This programme, in which 13 projects from different research institutes are participating, is the first occasion in which the influence of the nature of the specimen can be extensively investigated. The influence of the specimen production and preparation procedures on the compressive strength and the number of cycles to failure for high-performance (HPC) and ultra-high performance concrete (UHPC) were investigated within the framework of a round robin test in which seven laboratories participated.

\section{Experimental programme}

\subsection{Concrete and specimen}

The concretes used in the round robin test are the reference concretes developed and used within the SPP 2020. These are a HPC and an UHPC with 28-day mean compressive strengths of about 113 and $170 \mathrm{MPa}$, respectively. The complete composition of the reference concretes is given in Table 1 .

The mixing process of the raw materials, all supplied from a single production batch, was also given at the participant laboratories. Seven laboratories were involved: They were free to use their own concrete mixers and their own technique to compact the concrete in the formworks. However, the formworks (PVC) were the same type from the same manufacturer for all participants. The participating laboratories were anonymized by numbering them from 1 to 7. Specifically, the first four laboratories contributed by providing HPC specimens and the other three by providing UHPC specimens, all centrally tested in Hanover. The nominal specimen dimensions ready for test were $60 \mathrm{~mm}$ in diameter and $180 \mathrm{~mm}$ in height. Four different batch mixers were used, three of them with a vertical axis of rotation and one, at laboratory 2, with a horizontal axis. Laboratories 1, 4, 6 and 7 used the same type of mixer. Each laboratory used a similar concrete compaction technology and technique with slightly different vibration frequencies but with a different total vibration duration for the HPC concrete. The techniques used for the specimen production in the individual laboratories are summarised in Table 2. 
Table 1 Concrete composition

\begin{tabular}{lll}
\hline Content & HPC & UHPC \\
\hline CEM I 52.5 R-HS/NA & $500.00 \mathrm{~kg} / \mathrm{m}^{3}$ & $795.40 \mathrm{~kg} / \mathrm{m}^{3}$ \\
Microsilica & - & $168.60 \mathrm{~kg} / \mathrm{m}^{3}$ \\
Quartz sand $(0 / 0.5 \mathrm{~mm})$ & - & $198.40 \mathrm{~kg} / \mathrm{m}^{3}$ \\
Fine sand $(0 / 0.5 \mathrm{~mm})$ & $75.00 \mathrm{~kg} / \mathrm{m}^{3}$ & $971.00 \mathrm{~kg} / \mathrm{m}^{3}$ \\
Sand $(0 / 5 \mathrm{~mm})$ & $850.00 \mathrm{~kg} / \mathrm{m}^{3}$ & - \\
Basalt $(2 / 5 \mathrm{~mm})$ & $350.00 \mathrm{~kg} / \mathrm{m}^{3}$ & - \\
Basalt $(5 / 8 \mathrm{~mm})$ & $570.00 \mathrm{~kg} / \mathrm{m}^{3}$ & - \\
Superplasticizer & $5.00 \mathrm{~kg} / \mathrm{m}^{3}$ & $24.10 \mathrm{~kg} / \mathrm{m}^{3}$ \\
Stabilizer & $2.85 \mathrm{~kg} / \mathrm{m}^{3}$ & - \\
Water & $176.00 \mathrm{~kg} / \mathrm{m}^{3}$ & $187.90 \mathrm{~kg} / \mathrm{m}^{3}$ \\
28-d Mean compressive strength $(100 \mathrm{~mm}$ cube $)$ & $\sim 113 \mathrm{MPa}$ & $\sim 170 \mathrm{MPa}$ \\
\hline
\end{tabular}

Table 2 Specimen production and preparation techniques

\begin{tabular}{|c|c|c|c|c|c|c|c|}
\hline Laboratory & 1 & 2 & 3 & 4 & 5 & 6 & 7 \\
\hline Concrete & HPC & & & & UHPC & & \\
\hline Concrete mixer & $\begin{array}{c}\text { Pemat ZK } \\
150 \mathrm{HE}\end{array}$ & $\begin{array}{l}\text { CEM } 60 \mathrm{~S} \\
\text { Elba }\end{array}$ & $\begin{array}{l}\text { UEZ ZM } \\
100\end{array}$ & $\begin{array}{c}\text { Pemat ZK } \\
150 \mathrm{HE}\end{array}$ & Bucket mixer & Pemat ZK $150 \mathrm{HE}$ & $\begin{array}{c}\text { Pemat ZK } \\
150 \mathrm{HE}\end{array}$ \\
\hline $\begin{array}{l}\text { Max. material (dry) } \\
{[1]}\end{array}$ & 170 & 60 & 200 & 170 & 20 & 170 & 170 \\
\hline Engine Power [kW] & 4 & 3.3 & 4 & 4 & 2.0 & 4 & 4 \\
\hline Formwork & PVC & & & & & & \\
\hline $\begin{array}{c}\text { Compacting } \\
\text { technique }\end{array}$ & $\begin{array}{l}\text { Shaking } \\
\text { table }\end{array}$ & $\begin{array}{l}\text { Shaking } \\
\text { table }\end{array}$ & $\begin{array}{l}\text { Shaking } \\
\text { table }\end{array}$ & $\begin{array}{l}\text { Shaking } \\
\text { table }\end{array}$ & Shaking table & $\begin{array}{l}\text { Shaking } \\
\text { table }+ \text { Tapping }\end{array}$ & $\begin{array}{l}\text { Shaking } \\
\text { table }\end{array}$ \\
\hline $\begin{array}{l}\text { Vibration } \\
\text { frequency }[\mathrm{Hz}]\end{array}$ & 50 & n.a & $40-80$ & $70-90$ & 50 & n.a & $70-90$ \\
\hline $\begin{array}{c}\text { Total vibration } \\
\text { duration }[\mathrm{s}]\end{array}$ & 120 & $80-120$ & 135 & 60 & 120 & 120 & 120 \\
\hline $\begin{array}{l}\text { Formwork } \\
\text { removing system }\end{array}$ & Form cutting & $\begin{array}{l}\text { Form } \\
\text { cutting }\end{array}$ & $\begin{array}{l}\text { Form } \\
\text { cutting }\end{array}$ & $\begin{array}{l}\text { Spec. push } \\
\text { out }\end{array}$ & $\begin{array}{l}\text { Spec. manual } \\
\text { push out }\end{array}$ & Spec. push out & $\begin{array}{l}\text { Spec. push } \\
\text { out }\end{array}$ \\
\hline $\begin{array}{l}\text { "O" specimen } \\
\text { preparation }\end{array}$ & SG & SGP & SG & SG & SG & $\mathrm{SG}^{*}$ & SG \\
\hline $\begin{array}{l}\text { "R" specimen } \\
\text { preparation }\end{array}$ & SP & & & & & & \\
\hline
\end{tabular}

S: Sawing; G: Grinding (one side at a time); $G^{*}$ : Grinding two sides simultaneously; P: Polishing

The timing for the concrete curing and the removal of the formworks has been set as follows for all laboratories and concretes. After filling the formwork and compacting the concrete, the specimens initially remained covered in the formwork for $48 \mathrm{~h}$. The laboratories producing UHPC used a technique that involves the mechanical or manual pushing of hardened concrete specimens out of the formworks.
Among the laboratories that produced HPC specimens this technique was only used by laboratory 4 , while the remaining laboratories cut the formwork vertically. The specimens removed from the formworks were then stored in the climatic chamber at standard conditions $\left(20^{\circ} \mathrm{C} / 65 \%\right.$ R.H.). Information concerning the quantities of the raw materials used in the concrete production, the concrete slump according to the DIN 
EN 12,350-5:2009-08 standard and the 28-d compression strength according to DIN EN 12,390-13:2014-06 are made available by the laboratories' production protocols.

The preparation of the specimens was carried out when the concrete had reached 14 days of curing. Each participating laboratory prepared only half of the specimens produced by means of its own techniques normally used. Consequently, this group of specimens is identified by the letter "O" (Own preparation technique). The other half of the specimens of each laboratory were prepared in the laboratory of the Institute of Building Materials Science in Hannover using the technologies available there. This group was, thus, identified by the letter " $\mathrm{R}$ " (Reference preparation technique). The procedure for the preparation of the specimens consists generally of sawing a few centimetres off at the upper and lower ends of the specimens to remove areas that could have been disturbed by the production process. The test surfaces of the concrete cylinders were then parallel ground and/or polished individually. The techniques used by each laboratory for the preparation of the specimens are summarised in Table 2 .

It appears that all specimens of the "O" sets in the laboratories were prepared by sawing and grinding, with only those in laboratory 2 being polished additionally. Only laboratory 6 ground the upper and lower test surfaces using two parallel simultaneous grinding discs. The reference preparation technique consisted of accurate sawing and polishing of the test surfaces.

The specimens were sent to the laboratory in Hannover with a concrete age of at least 35 days. They were wrapped in polyethylene film to protect them from drying during transportation. Shockproof boxes provided by the central laboratory of Hannover were used for the transportation. The weight of the specimens was determined before and after shipping to check for any influence on their moisture content due to transport.

The concrete production in the laboratories was scheduled to obtain a minimal concrete age difference of the specimens on the day of the test. Following this procedure, the HPC specimens were tested between 77 and 84 days and the UHPC specimens between 84 and 103 days. Since the specimens within each concrete group are of similar age, the influences of concrete aging on the compressive strength can be considered irrelevant. This is also verified by the formulation of the development of strength with time indicated by the Model Code 2010.

\subsection{Main investigations}

The main investigations into the two groups of specimens (O: Own preparation technique; R: reference preparation technique) consist of monotonically increasing and cyclic compression load tests, both carried out in the same servohydraulic testing machine with a $1 \mathrm{MN}$ actuator.

Six specimens from each group were tested under force-controlled conditions at a constant speed of $0.5 \mathrm{MPa} / \mathrm{s}$. The resulting mean compressive strength value was used as the reference strength for the following cyclic load tests.

The cyclic load tests were performed on at least six specimens using a sinusoidal cyclic load with a frequency of $f_{\mathrm{p}}=1 \mathrm{~Hz}$. Only one cyclic load with a minimum stress level of $S_{\mathrm{c}, \min }=0.05$ and maximum stress level of $S_{\mathrm{c}, \max }=0.75$ was investigated.

The deformations in both types of tests were measured continuously by three laser distance sensors positioned around the specimen at $0^{\circ}, 120^{\circ}$ and $240^{\circ}$. The surface temperature during the cyclic load tests was recorded by means of thermocouples at the midheight of the specimen and one centimetre above/below the upper and lower pressure plates, and the ambient temperature in the testing chamber was recorded as well. These measurements were used to monitor the tests and will not be used in the analysis in this paper as the focus is on the compressive strength and the number of cycles to failure. An example of the test set-up is shown in Fig. 1, where the laser sensor protection shields have been temporarily removed for better visibility.

\subsection{Complementary investigations}

Before the compression and fatigue tests were carried out, the geometrical characteristics of the cylindrical specimens, resulting from the various preparation techniques used, were measured. In addition to the diameter and height of the test specimens, the flatness of the test surfaces and the perpendicularity of the lateral surface of the cylinder to the test surface were also measured according to [32]. The perpendicularity is described as the maximum deviation $\left(v_{\max }\right)$ of a 
(a)

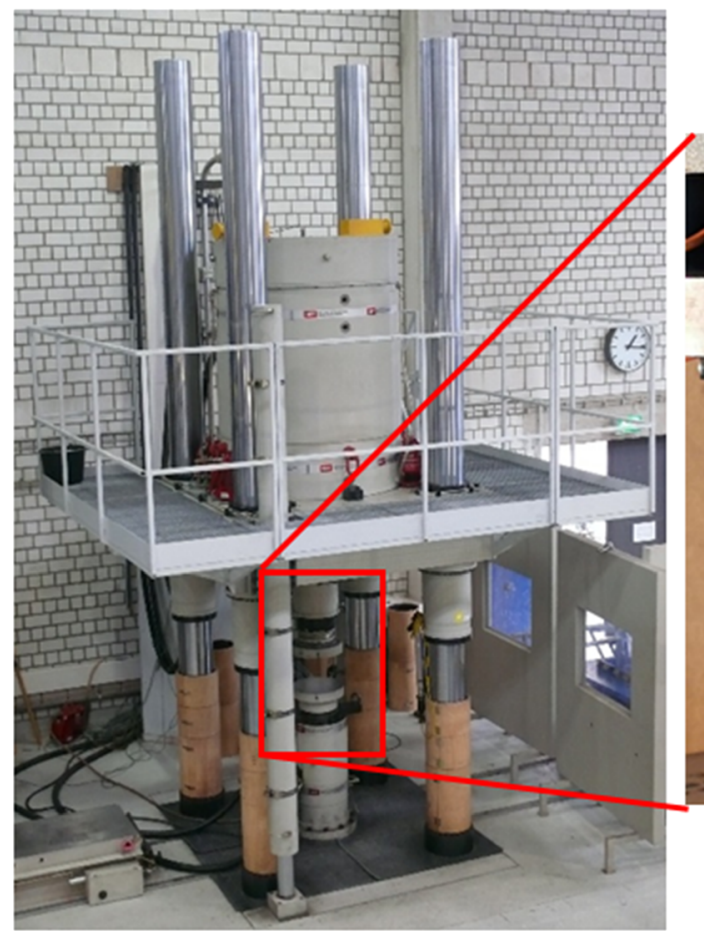

(b)

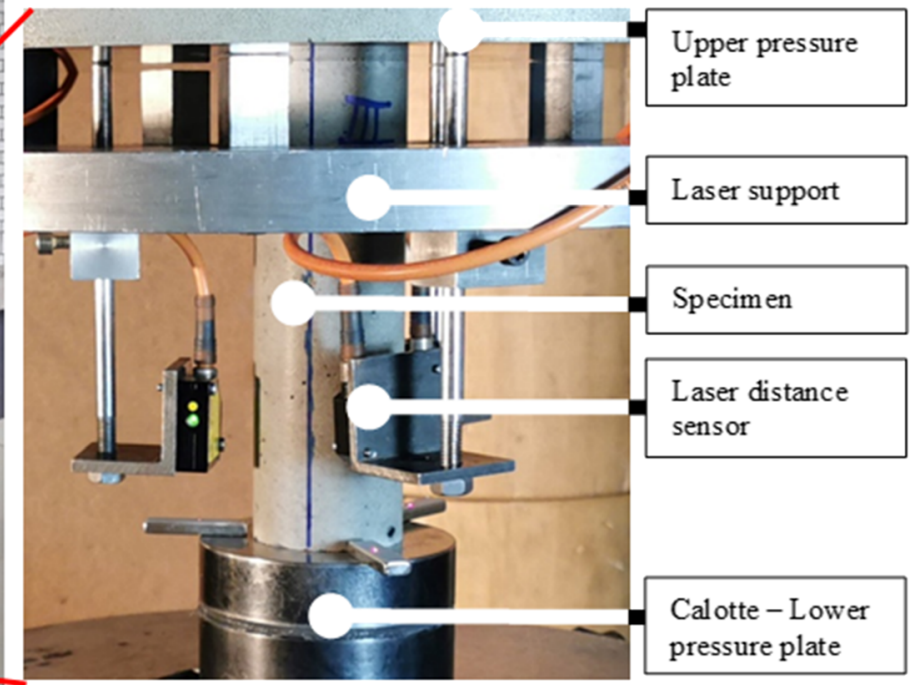

Fig. 1 Servohydraulic testing machine with $1 \mathrm{MN}$ actuator (a) and measurement set-up (b) for the compressive strength and the cyclic load tests

point on the cylinder shell from the lateral reference plane and expressed in millimetres.

In addition, the surface roughness of both test surfaces, defined according to ISO 25178, has been measured using the 3D laser scanning confocal microscope "VR-5000" by KEYENCE. The determined parameter related to the test surfaces of the specimens has been called the "effective area ratio" (EAR), and aims to identify surface edge imperfections, such as edge breaks, that cause a reduction of the contact surface with the loading plates of the test machine and, in the worst-case scenario, anomalies in the stress flow inside the specimen itself. The "effective area ratio" is the ratio between the area excluding edge imperfections, determined by the profilometer, and the flawless area, calculated using the average diameter of the specimen.

The sound velocity (pulse velocity) through the concrete specimens was measured to characterise the concrete microstructure of each specimen. According to the Impact Resonance Method the specimen was mechanically stimulated with the impulse of a small metal ball at one end of the specimen (Fig. 2). A

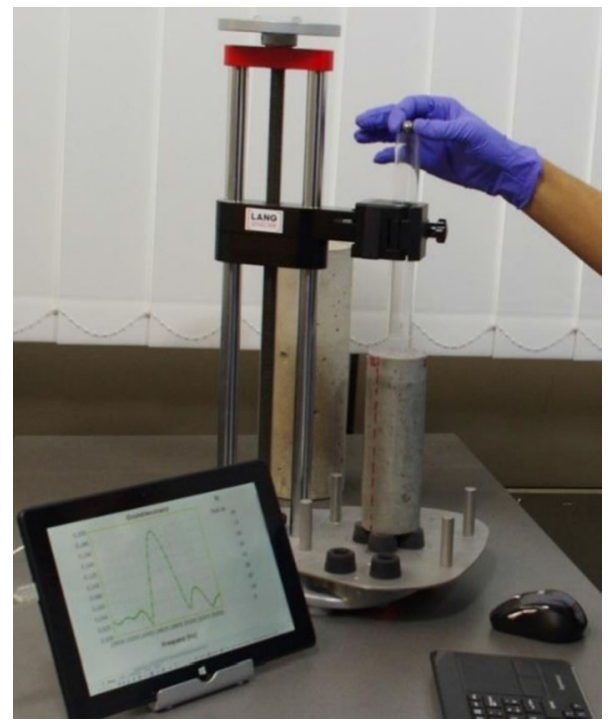

Fig. 2 Measuring procedure for the determination of sound velocity with the Lang RA 100 [35]

microphone at the other end of the specimen perceived the vibrations so that the sound velocity could be determined $[33,34]$. The measurement was performed 
by means of the non-destructive testing equipment "RA 100 Concrete" by Lang Sensorik (ASTM C215, BS 1881-209).

\section{Test results}

\subsection{Compressive strength and number of cycles to failure}

A total of 48 specimens were investigated under compressive load and 53 specimens were investigated under compressive cyclic load within the framework of this investigation of HPC.

The results of the compression tests and the cyclic load tests carried out on HPC specimens from laboratories 1 to 4 are shown in Fig. 3: The whiskers indicate the standard deviations, while the red and blue dots represent the mean values obtained from the specimen sets "O" and "R", respectively. Additionally, the standard deviation is also represented on the secondary co-ordinate system on the right vertical axis for the sake of clarity.

Considering the results obtained from the specimens from all the laboratories, an overall mean compressive strength value of $98.7 \mathrm{MPa}$ is obtained, while the overall standard deviation is $11 \mathrm{MPa}$, which is higher than the standard value between 6 and $8 \mathrm{MPa}$ stated by [36] for the production of HPC. The lowest and highest mean values are 81.6 and $116.2 \mathrm{MPa}$ obtained respectively from the specimen sets $1-\mathrm{O}$ and $3-\mathrm{R}$, while the mean values obtained from the specimens from laboratories 2 and 4 are closer to the overall mean.

The compressive mean values obtained from specimen sets " $\mathrm{R}$ " are higher than those obtained from specimen sets "O" for all laboratories. Such a difference is particularly strong in the results obtained from specimens of laboratory 1 . This indicates a positive influence of the reference technique, i.e. of the preparation by careful sawing and polishing, on the compressive strength.

Regarding data scattering, the comparison between the two sets " $O$ " and " $\mathrm{R}$ " for laboratories 2, 3 and 4 shows similar results, which would indicate no influence of the preparation technique. However, the scattering of results obtained from laboratory 1 specimens prepared according to the reference technique is considerably lower than the one obtained from the specimens prepared by the laboratory itself. This indicates a negative influence of the preparation technique used in laboratory 1 on the scattering. The (a) HPC-Compressive strength

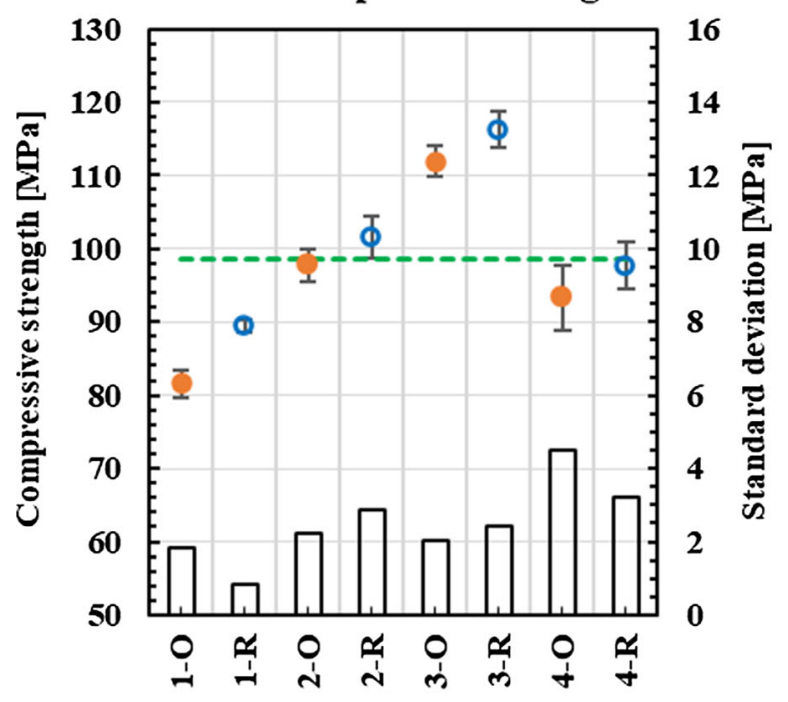

Laboratory - Preparation tech.

$\square$ Standard deviation $\quad$ Mean value "O" (b) HPC - Number of cycles to failure

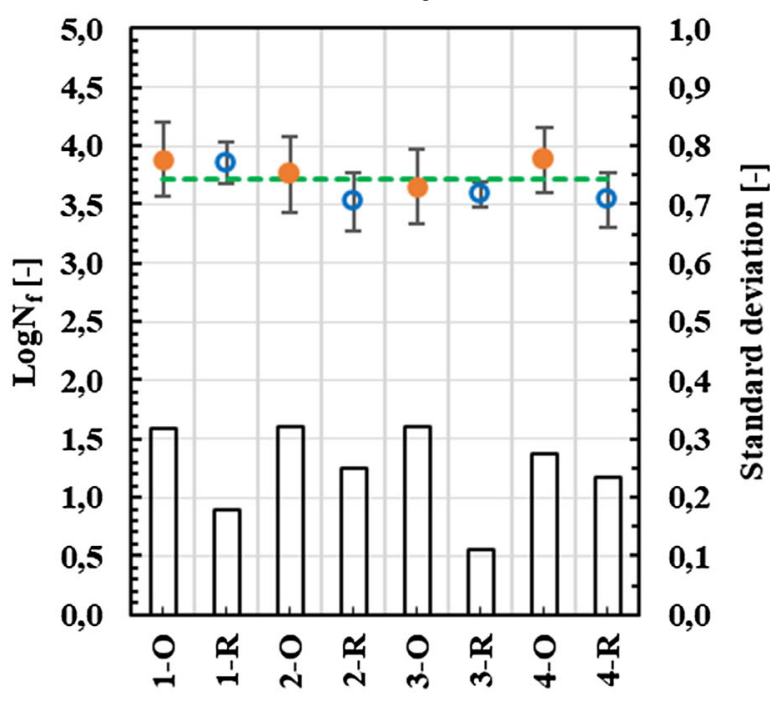

Laboratory - Preparation tech.

- Mean value " $\mathrm{R}$ " ------Overall mean

Fig. 3 HPC - a Compressive strength, b Number of cycles to failure 
geometrical characteristics of the specimens resulting from the preparation techniques are further investigated in the next section for a better understanding of these results.

The resulting overall number of cycles to failure mean is 3.713 on a logarithmic scale with an overall standard deviation of 0.28. It is obvious from Fig. 3b that the mean values of the different specimen sets do not deviate significantly from the overall mean value and remain within the distance of one standard deviation from it. A closer look at the standard deviations for each specimen set shows that the standard deviation of the specimens prepared according to the reference technique is generally smaller than that from the set of specimens prepared directly by the laboratories.

Laboratories 5, 6 and 7 produced UHPC specimens. A total of 37 specimens were investigated under compressive load and 38 were investigated under compressive cyclic load in the central laboratory.

The results of the compression tests and the cyclic load tests carried out on UHPC specimens from laboratories 5 to 7 are shown in Fig. 4 using the same graphical representation as for the HPC results in Fig. 3.

\section{(a) UHPC - Compressive strength}

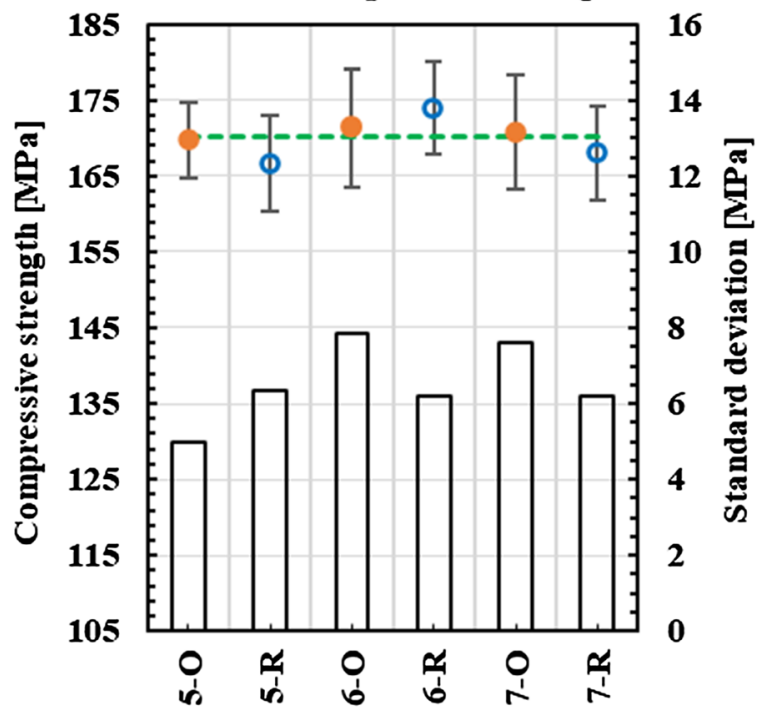

Laboratory - Preparation tech. (b) UHPC - Number of cycles to failure

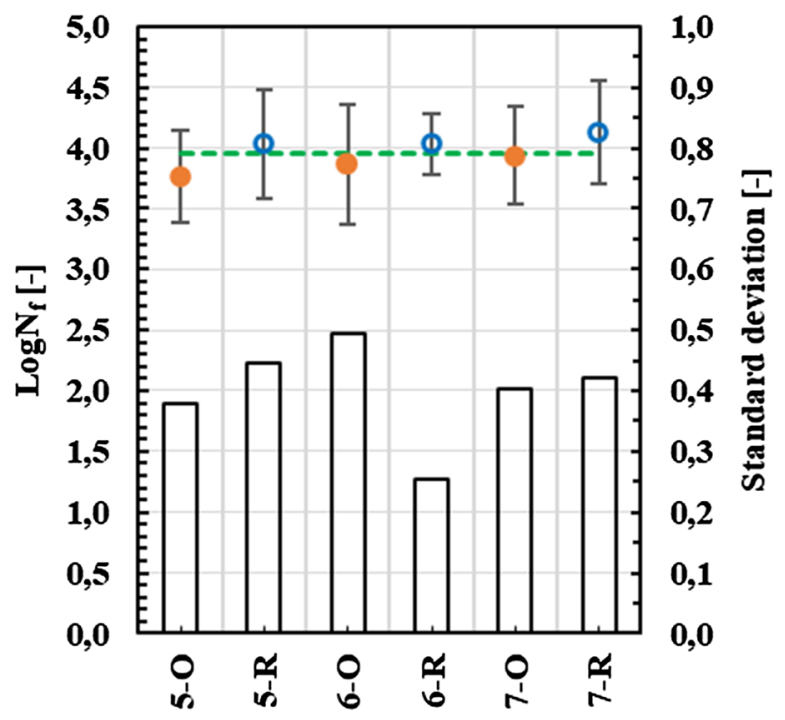

Laboratory - Preparation tech.

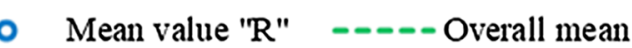

Fig. 4 UHPC - a Compressive strength, b Number of cycles to failure

The overall mean value obtained from the compression tests is $170.1 \mathrm{MPa}$ with an overall standard deviation of $6.6 \mathrm{MPa}$, which is a typical value according to [36]. In contrast to HPC, the UHPC specimens produced by different laboratories show a similar mean compressive strength with no significant deviation from the overall mean value. This indicates no influence of the concrete production on the concrete strength. The scattering obtained by the single sets of UHPC specimens represented in terms of standard deviation is between about 5 and $8 \mathrm{MPa}$, which is higher than the scattering obtained by the sets of HPC specimens, i.e. between about 1 and $4 \mathrm{MPa}$.

The overall mean value of the number of cycles to failure on a logarithmic scale is 3.960 with an overall standard deviation of 0.40 . The mean values of the number of cycles to failure of each specimen set are close to the global mean. Therefore, the production techniques used by the three laboratories producing UHPC had no influence on the cyclic load tests.

However, Fig. 4b shows that the mean values of the specimen sets prepared using the reference technique " $\mathrm{R}$ " are slightly higher than those obtained from the specimen sets "O" prepared by the laboratories themselves. This can be interpreted as a slight positive

\section{Standard deviation}


influence of the preparation technique " $R$ " by careful sawing and polishing of the specimens.

Regarding the scattering of the number of cycles to failure, the standard deviations shown in Fig. 4b are not clearly dependent on the type of preparation used. However, it is possible to see that the preparation technique used by laboratory 6 induces the greatest dispersion in the results. Furthermore, it should be noted that the scattering of the cyclic load tests obtained by the single sets of UHPC specimens, with exception of set 6-R, is between about 0.4 and 0.5 , which is greater than that obtained from HPC specimens, which is between about 0.1 and 0.3 .

\subsection{Specimens geometrical characteristics}

The geometrical characteristics of all the specimens were assessed as described in Sect. 2.3. No significant differences were recorded regarding the specimen diameter because all the laboratories used the same type of formwork from the same manufacturer. Excluding the preparation technique of laboratory 2, the laboratories' preparation techniques allowed the preparation of specimens with a height equal to the imposed nominal height of $180 \mathrm{~mm}$ with a standard deviation of about $0.3 \mathrm{~mm}$. The test specimens in laboratory 2 were an average of $2 \mathrm{~mm}$ higher than the nominal height with a standard deviation of $2.5 \mathrm{~mm}$. The assessment of the test surface flatness of all HPC and UHPC specimens gave no evidence of deviations, which means that all the preparation techniques allow the realisation of perfectly flat surfaces, according to the definition of [32].

The results of the measurements of the three most significant geometric parameters, namely, perpendicularity of the lateral surface, roughness and effective area ratio, are shown in Fig. 5 for each set of specimens and laboratory and both HPC and UHPC (lab 1 to 4: HPC, lab 5 to 7: UHPC).

The analysis of perpendicularity shows that laboratories 2 to 7 can obtain deviations comparable to those using the reference preparation technique with a maximum deviation of less than a millimetre. The technique used by laboratory 1 is less accurate and causes an average deviation of about $1.2 \mathrm{~mm}$, which is almost three times greater than that obtained by preparing the specimen set " $1-\mathrm{R}$ " using the reference technique.

By analysing the roughness of the test surfaces, it is possible to easily identify the laboratories using the polishing method, seen as they will be the ones where the lowest values of surface roughness are measured: laboratory 2 and the reference technique. Although laboratory 5 has indicated the use of grinding in the (a)

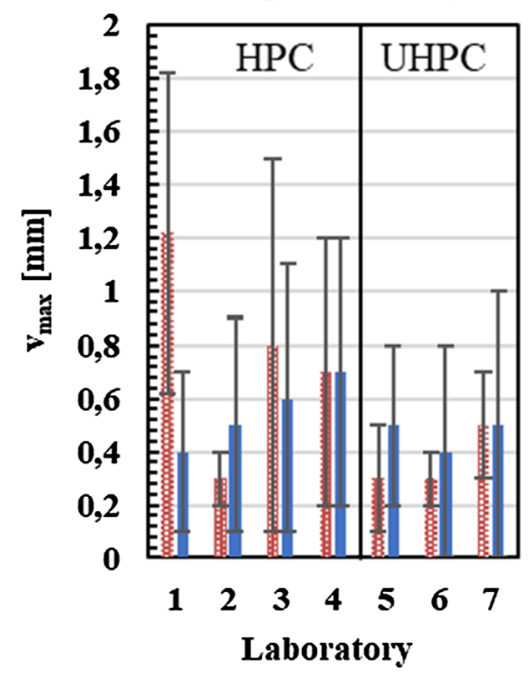

(b)

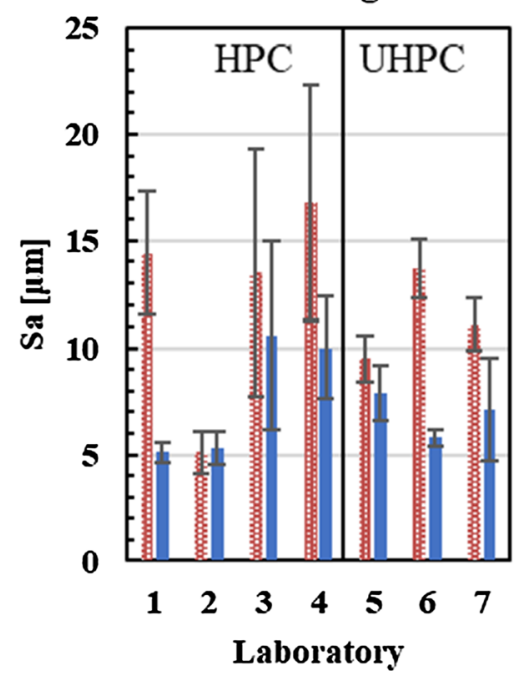

(c) Effective Area Ratio

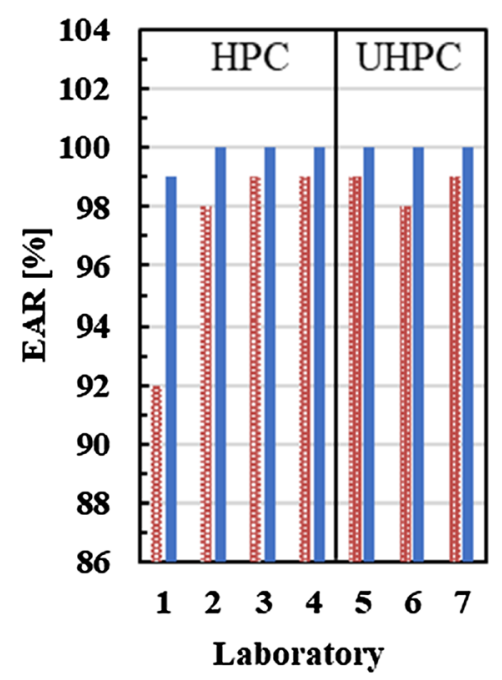

珠 O: Own preparation technique $\quad=\mathrm{R}$ : reference preparation technique

Fig. 5 Geometrical characteristics - a Perpendicularity of the specimens, b Surface roughness of the test surfaces, c Effective Area Ratio (EAR) 
protocol, the results obtained are similar to those of the reference polishing technique. The use of grinding by laboratories 1, 3, 4, 6 and 7 lead to a significantly higher roughness than that achieved by polishing.

The results of the effective area ratio parameter, which aims to identify local imperfections and breaks in the edges of test surfaces, are meaningful. The reference technique generally allows one to obtain specimens with intact edges that do not reduce the contact surface with the pressure plates of the test machine. The techniques used by laboratories $3,4,5$ and 7 caused slight imperfections that reduced the contact surface by an average of about $1 \%$. An average reduction of approximately $2 \%$ is recorded for specimens prepared by laboratories 2 and 6 , while the average reduction recorded for specimens from laboratory 1 is about $8 \%$ and, thus, much higher.

The extent of the imperfections found on the specimens prepared by laboratory 1 is given in the example shown in Fig. 6. The picture of the test surface of a specimen is on the left-hand side and the 3D image taken by the profilometer is on the righthand side. The breakage of a part of the edge of the specimen is evident and of considerable size. In addition, there are small imperfections along the entire edge that further reduce the contact surface with the pressure plates of the machine.

On the contrary, Fig. 7 shows an example of a test surface of a specimen produced by the same laboratory 1 but prepared with the accurate sawing and polishing of the reference technique. This example shows that the edges are undamaged. Consequently, there is no reduction of the contact surface with the load plates of the test machine.

\subsection{Concrete microstructure characterization}

The quality of the microstructure of the hardened concrete of the specimens is characterised by the measurement of the pulse velocity just before the compression tests.

The resulting compressive strength and the corresponding pulse velocity measured of each specimen tested that was prepared according to the reference technique ("R" specimens) are depicted in Fig. 8 for both HPC and UHPC.

Considering the production batches separately, the pulse velocity values obtained within each production batch are homogeneous. Consequently, it is possible to exclude issues or anomalies during the production of concrete in the participating laboratories.

Regarding the HPC results, it is possible, in a first approximation, to recognise a linear correlation between the pulse velocity and the compressive strength. The specimens from laboratory 3 show the highest compressive strength, about $120 \mathrm{MPa}$, and the highest pulse velocity, about $4640 \mathrm{~m} / \mathrm{s}$, whereas the specimens from laboratory 1 show the lowest strength, about $90 \mathrm{MPa}$, and the lowest pulse velocity, about $4320 \mathrm{~m} / \mathrm{s}$. The compressive strength of the specimens
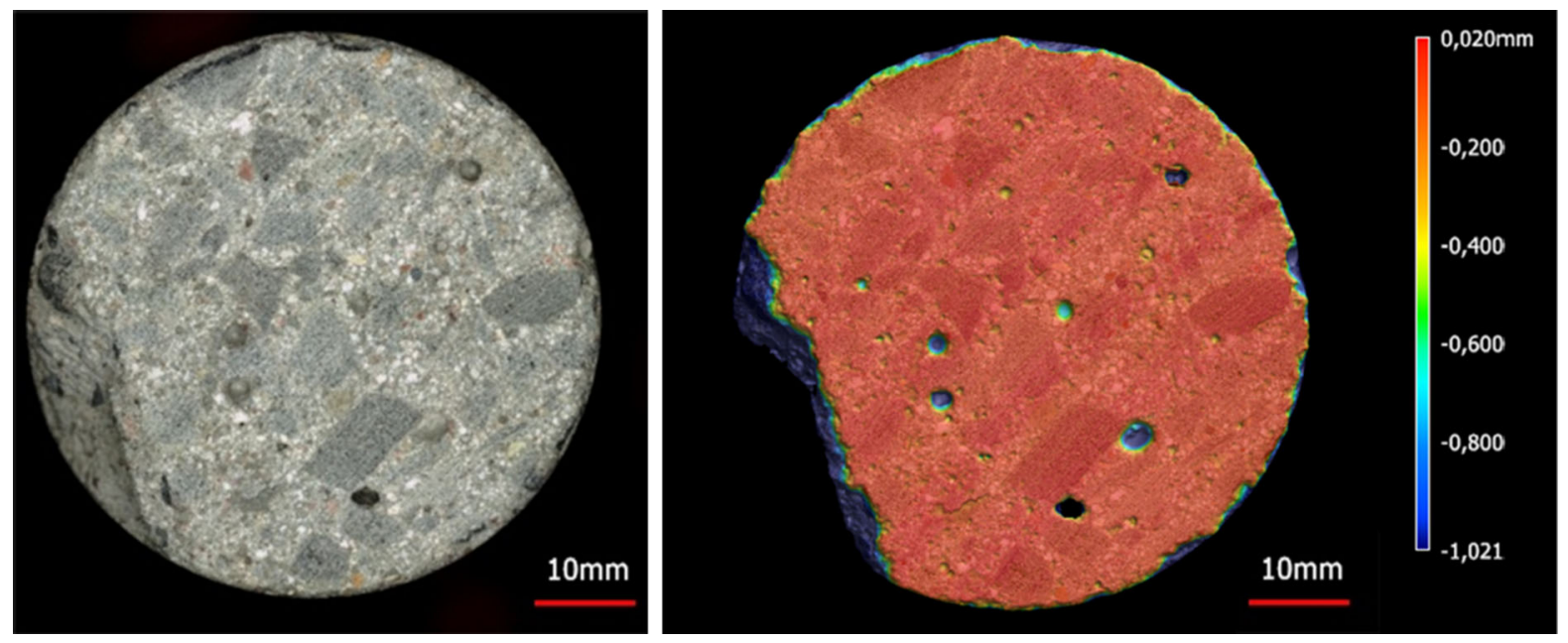

Fig. 6 Example of a HPC specimen from laboratory 1 prepared using their own preparation technique (SG). On the left: test surface. On the right: $3 \mathrm{D}$ profilometer 

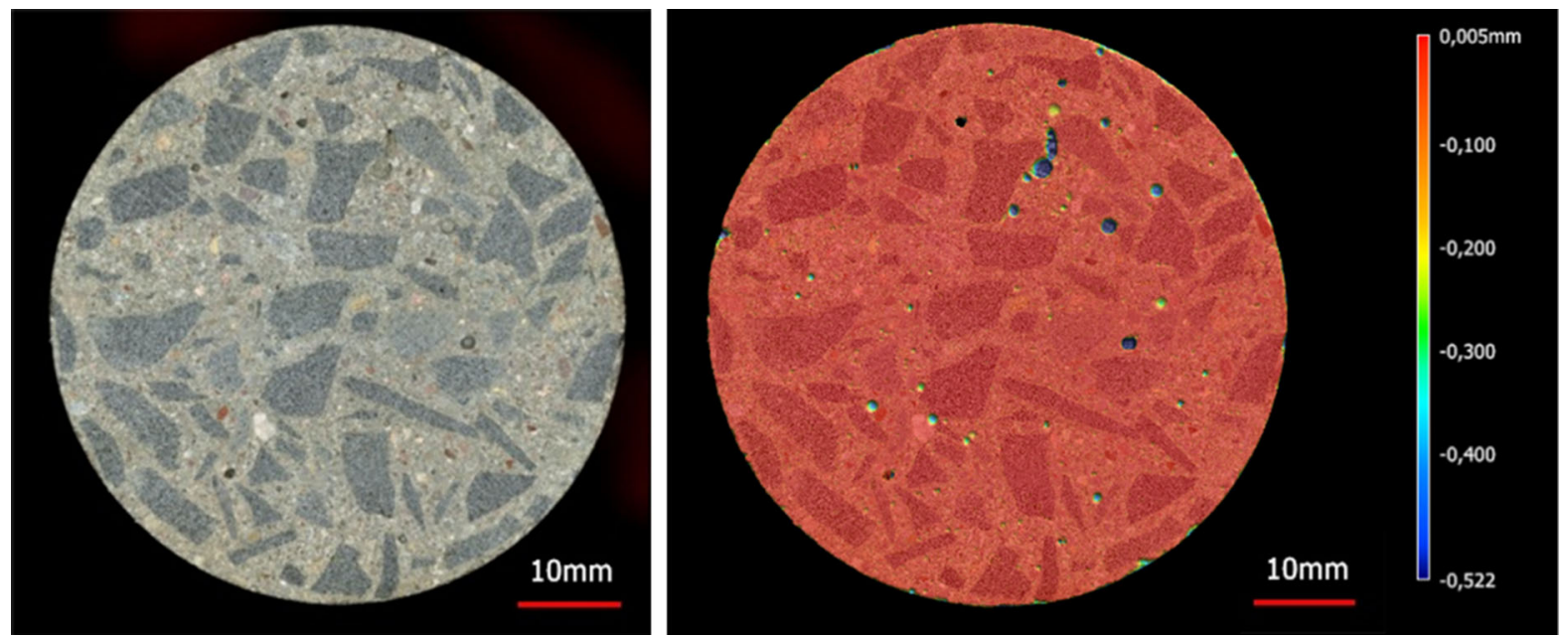

Fig. 7 Example of a HPC specimen from laboratory 1 prepared using the reference preparation technique (SP). On the left: test surface. On the right: $3 \mathrm{D}$ profilometer

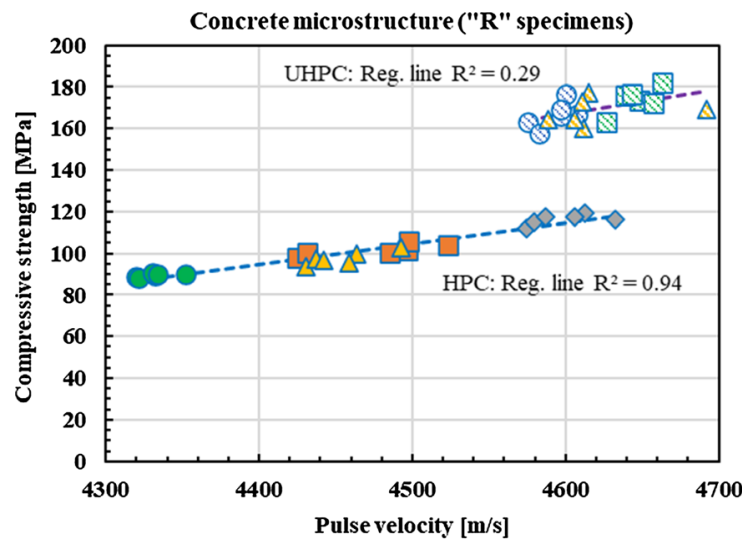

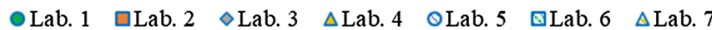

Fig. 8 HPC (Lab 1 to 4) and UHPC (Lab 5 to 7)-Concrete microstructure characterisation

and the corresponding pulse velocities from laboratory 2 and 4 lie in the same interval. The results also show that the three groups of results, namely laboratory 1,3 and the group of laboratories 2 and 4, are well separated from each other.

Regarding the results obtained from the UHPC specimens, the graph shows that that they are very close to each other and that a clear correlation, such as in the case of HPC, is not present. The maximum and minimum mean compressive strengths are about 167 and $174 \mathrm{MPa}$, respectively, while the pulse velocity has a range from 4580 to $4690 \mathrm{~m} / \mathrm{s}$, which is smaller than the range of the HPC and indicates a similarity of the concrete microstructures produced from different batches.

Taken together, these results suggest an influence of the production techniques used by the laboratories producing HPC specimens on the concrete microstructure, thus, on the compression strength, whereas the techniques used to produce the UHPC have no remarkable influence on the concrete microstructure or the compressive strength.

\section{Analysis and discussion}

\subsection{HPC}

The results presented in Fig. 2 show that laboratories have an influence on the concrete production and, therefore, on the compressive strength: laboratories 2 and 4 produced specimens with similar strength, while laboratories 1 and 3 produced specimens with the lowest and highest strength, respectively. There is a statistically significant difference between the production batches, which is proved by applying the ANOVA analysis to the results from the specimens prepared using the reference technique. The trend shown in Fig. 3.a is confirmed and justified by the characterisation of the microstructure by the pulse velocity: Fig. 8 shows how the production of the laboratories leads to three different types of microstructures and, thus, to three compressive 
strength groups. In the production protocols from laboratory 4, there are indications of a higher moisture content in the aggregates used than in the dried aggregates indicated by the concrete production guidelines provided by the central laboratory. Therefore, it is possible to assume a negative influence on the compressive strength caused by a higher total water content than required due to incompletely dried aggregates. Furthermore, there is a notable difference between the techniques used for compacting concrete used by the laboratories (Table 2), which can contribute to influence the compressive strength.

As far as the influence of the preparation techniques is concerned, the specimens prepared using the reference technique with accurate sawing and polishing have geometrical characteristics with reduced irregularities and a higher accuracy. This provides a positive effect on the compressive strength that can be noted by comparing the results obtained from the " $R$ " and "O" specimen sets from each laboratory: the mean value obtained from the " $\mathrm{R}$ " set is greater than that obtained from the "O" set. This result is also statistically confirmed by the classical t-test.

Figure 3.b shows that the mean values of the number of cycles to failure of the specimen sets from the four laboratories producing HPC are all in the immediate proximity of the overall mean value of the number of cycles to failure. This indicates two facts: the evident influence of the concrete production on the concrete strength is not to be found in the cyclic load tests and the specimen preparation techniques have no influence on the mean number of cycles to failure. The second point is also supported statistically by applying the classical t-test to the results of " $\mathrm{R}$ " and "O" for each laboratory specimen set. These findings match the explanation mentioned in [37]: the maximum and minimum stresses applied during the cyclic load tests are obtained from specimens tested under compression with the same characteristics as those specimens tested under fatigue load, so that the mean values of the number of cycles to failure obtained is independent of the specimen concrete and preparation technique used in the present round robin test.

Considering the scattering of the number of cycles to failure represented by the standard deviation in Fig. 3.b, it appears that the sets of specimens prepared using the reference technique (sets "R") have less scattering than those prepared by the individual laboratories (sets "O"). This can be explained by the higher uniformity and accuracy of the geometrical characteristics of the " $R$ " specimen sets as shown in Fig. 5. Hence, the preparation by accurate sawing and polishing has a positive influence by reducing the scattering of the number of cycles to failure.

\subsection{UHPC}

The laboratory-dependent production of concrete has no influence on the compressive strength of the UHPC specimens. This is shown by the graph in Fig. 4.a in which the mean compressive strength values obtained from the specimen sets from the three laboratories producing UHPC are in the immediate proximity of the overall mean strength. It is also supported by the ANOVA statistical analysis and confirmed by the homogeneity of the UHPC microstructures characterised by the pulse velocity shown in Fig. 8 .

Furthermore, it is also possible to deduce from the same previous considerations of the results from Fig. 4.a that there is no influence by the preparation techniques used in this round robin test on the mean compressive strength. This is supported by the ANOVA analysis and even more significantly by the t-test applied to the " $\mathrm{R}$ " and "O" couples of results for each laboratory, which do not reveal any statistically significant influences. Considering the scattering showed in Fig. 4.a, there may be a positive effect of polishing from the reference technique, which allows the preparation of specimens with more accurate geometrical characteristics.

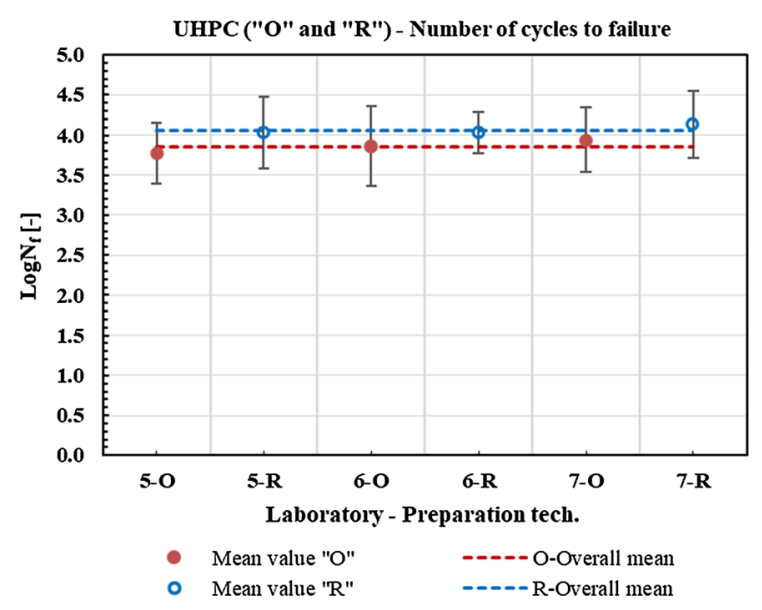

Fig. 9 UHPC number of cycles to failure-Influence of the preparation technique ("O" and " $\mathrm{R}$ "). 
The detailed representation of Fig. 9 shows that all the mean values obtained from the specimens prepared accurately using the reference technique tend to reach a slightly higher number of cycles to failure than those obtained from specimens prepared by the laboratories themselves. A positive effect of polishing on fatigue strength may be present.

As shown in Fig. 4.b, it is not possible to identify a clear influence of the preparation techniques used on the scattering of the number of cycles to failure. However, the technique used by laboratory 6 induces an anomaly in the integrity of the edges of the test surface in the specimen set $6-\mathrm{O}$, identified by the effective area ratio parameter with a value of $98 \%$, which is considerably lower than the $100 \%$ reached by the 6- $\mathrm{R}$ specimen set and may be considered responsible for the greater scattering of the cyclic load test results.

Finally, considering each specimen set, a comparison of the two concretes shows that the scatterings of the compressive strength and the number of cycles to failure obtained from UHPC specimens are greater than those obtained from HPC specimens.

\section{Conclusions}

Tests carried out on concrete specimens for the determination of compressive strength and fatigue strength expressed in number of cycles to failure can be influenced by various factors as shown in the literature. The influence of the production and preparation techniques of HPC and UHPC specimens was extensively investigated in a round robin test involving seven different laboratories. The authors analysed the results of the tests under monotonically increasing load and cyclic compression load in relation to the microstructural and geometrical characteristics of the concrete specimens reaching the following main conclusions:

1. On one hand, the different techniques used to produce the HPC specimens have an influence on the compressive strength. On the other hand, the techniques used to produce UHPC specimens were similar to each other so that no relevant influence on the compressive strength tests results is present. The production techniques do not significantly affect the mean number of cycles to failure since the cyclic load tests are performed on specimens using the reference strength obtained from the respective production batch.

2. The preparation techniques have an influence on the test results: The preparation by accurate sawing and polishing allows specimens with uniform and accurate geometrical characteristics to be produced. Broken specimens obtained due to poor sawing and improper grinding/polishing resulting in damaged edges have a negative influence on the compressive strength. Moreover, they have a negative influence on the scattering of the tests under monotonically increasing load and cyclic compression load in terms of maximal strength and number of cycles to failure for both HPC and UHPC. With regard to the mean number of cycles to failure, there is no influence of the preparation techniques on the results obtained from the HPC specimens. There might be a positive influence of the polishing technique on the mean number of cycles to failure value obtained from UHPC specimens, which needs to be further investigated.

3. Considering each specimen set, the scattering of the compressive strength data and that of the number of cycles to failure obtained from UHPC specimens are greater than those obtained from HPC specimens.

Acknowledgements This research project was supported by the German Research Foundation (DFG) within the scope of Priority Programme 2020 "Cyclic deterioration of HighPerformance Concrete in an experimental virtual lab" (353531623). The authors would like to express their gratitude for the financial support. The authors would also like to thank the project partners for their cooperation and engagement.

Funding Open Access funding enabled and organized by Projekt DEAL. The work was funded by the German Research Foundation (DFG).

\section{Declarations}

Conflict of interest The authors declare that they have no conflicts of interest.

Open Access This article is licensed under a Creative Commons Attribution 4.0 International License, which permits use, sharing, adaptation, distribution and reproduction in any medium or format, as long as you give appropriate credit to the original author(s) and the source, provide a link to the Creative Commons licence, and indicate if changes were made. The images or other third party material in this article are included in the article's Creative Commons licence, unless indicated otherwise in a credit line to the material. If material is not included in the article's Creative Commons licence and your intended use is not permitted by statutory regulation or exceeds 
the permitted use, you will need to obtain permission directly from the copyright holder. To view a copy of this licence, visit http://creativecommons.org/licenses/by/4.0/.

\section{References}

1. Oneschkow N, von der Haar C, Hümme J et al (2018) Ermüdung von druckschwellbeanspruchtem Beton-Materialverhalten, Modellbildung, Bemessung. Beton Kalender 2018. Wiley-VCH Verlag GmbH \& Co. KGaA, Weinheim, Germany, pp 643-755

2. Weigler H, Freitag W (1971) Dauerschwell- und Betriebsfestigkeit von Konstruktionsleichtbeton. Bundesminister Fuer Verkehr

3. Klausen D (1978) Festigkeit und Schädigung von Beton bei häufig wiederholter Beanspruchung. Technische Hochschule Darmstadt, Darmstadt

4. Klausen D, Weigler H (1980) Damage to Plain Concrete Under Cyclic Compressive Loading. Durab Build Mater Compon. https://doi.org/10.1520/stp36092s

5. Hegger J, Roggendorf T, Goralski C, Roeser W (2014) Ermüdungsverhalten von Beton unter zyklischer Beanspruchung aus dem Betrieb von Windkraftanlagen. Fraunhofer-IRB-Verlag

6. Van Ornum JL (1907) The fatigue of concrete. Trans Am Soc Civil Eng 58:294-320

7. Gaede K (1962) Versuche über die Festigkeit und die Verformung von Beton bei Druckschwellbeanspruchung. Ernst \& Sohn, Berlin

8. Aas-Jakobsen K (1970) Fatigue of concrete beams and columns. Division of Concrete Structures, Norwegian Inst. of Technology, University

9. Holmen JO (1982) Fatigue of Concrete by Constant and Variable Amplitude loading. Division of Concrete Structures, Norwegian Inst. of Technology, University Trondheim

10. Hohberg R (2004) Zum Ermüdungsverhalten von Beton. Technische Universität Berlin, ehemalige Fakultät VIBauingenieurwesen und Angewandte Geowissenschaften

11. Breitenbücher R, Ibuk H (2006) Experimentally based investigations on the degradation-process of concrete under cyclic load. Mater Struct 39:717-724. https://doi.org/10. 1617/s11527-006-9097-9

12. Grünberg J, Lohaus L, Ertel C, Elsmeier K (2014) Ermüdung von UHPC unter ein- und mehraxialer Beanspruchung-Experimentelle Untersuchung und Entwicklung eines mechanischen Modells. In: Schmidt M, Fehling E, Fröhlich S, Thiemicke J (eds) Nachhaltiges Bauen mit ultrahochfestem Beton. Kassel University Press GmbH, Kassel, pp 453-478

13. Thiele M (2015) Experimentelle Untersuchung und Analyse der Schädigungsevolution in Beton unter hochzyklischen Ermüdungsbeanspruchungen. Bundesanstalt für Materialforschung und-prüfung (BAM)

14. Oneschkow N (2016) Fatigue behaviour of high-strength concrete with respect to strain and stiffness. Int J Fatigue 87:38-49. https://doi.org/10.1016/j.ijfatigue.2016.01.008

15. Petkovic G (1991) Properties of concrete related to fatigue damage: with emphasis on high strength concrete. Division of Concrete Structures, Norwegian Inst. of Technology, University

16. Grünberg J, Hansen M, Marx S, Schneider S (2017) Sachstandbericht-Grenzzustände der Ermüdung von dynamisch hoch beanspruchten Tragwerken aus Beton. Beuth Verlag $\mathrm{GmbH}$, Berlin

17. FIB-International Federation for Structural Concrete (1993) CEB-FIP Model Code 1990: Design Code. T. Telford, London

18. König G, Danielewicz I (1994) Ermüdungsfestigkeit von Stahlbeton-und Spannbetonbauteilen mit Erläuterungen zu den Nachweisen gemäß CEB-FIP Model Code 1990. Deutscher Ausschuss für Stahlbeton. https://doi.org/10. 2366/3714933

19. Lohaus L, Wefer M, Oneschkow N (2011) Ermüdungsbemessungsmodell für normal-, hoch- und ultrahochfeste Betone. Beton-und Stahlbetonbau 106:836-846

20. Fib-federation internationale du beton (2013) fib Model Code for Concrete Structures 2010. Wiley, New Jersy

21. Waagaard K (1981) Investigation of offshore concrete structures with respect to fatigue strength - Fatigue strength of offshore concrete structures, (Concrete structures for marine production, storage and transportation of hydrocarbons) COSMAR report No. PP2-1 and PP2-2

22. Aldakheel F, Tomann C, Lohaus L, Wriggers P (2019) Water-induced failure mechanics for concrete. Proc Appl Math Mech. https://doi.org/10.1002/pamm.201900140

23. Tomann C, Oneschkow N (2019) Influence of moisture content in the microstructure on the fatigue deterioration of high-strength concrete. Struct Concr 20:1204-1211. https:// doi.org/10.1002/suco.201900023

24. Oneschkow N, Hümme J, Lohaus L (2020) Compressive fatigue behaviour of high-strength concrete in a dry and wet environment. Constr Build Mater 262:119700

25. Schneider S, Hümme J, Marx S, Lohaus L (2018) Untersuchungen zum Einfluss der Probekörpergröße auf den Ermüdungswiderstand von hochfestem Beton. Beton Stahlbetonbau 113:58-67. https://doi.org/10.1002/best. 201700051

26. FIB-International Federation for Structural Concrete (1988) Fatigue of concrete structures state of the art report. Comité euro-international du béton, Lausanne

27. Raju NK (1969) Prediction of the fatigue life of plain concrete in compression. Build Sci 4:99-102. https://doi.org/ 10.1016/0007-3628(69)90010-3

28. Oh BH (1991) Fatigue life distributions of concrete for various stress levels. ACI Mater J 88:122-128

29. Minh-Tan Do, Omar C, Pierre-Claude A (1993) Fatigue behavior of high-performance concrete. J Mater Civ Eng 5:96-111. https://doi.org/10.1061/(ASCE)08991561(1993)5:1(96)

30. Urban S, Wagner R, Strauss A et al (2013) Monitoringbased lifetime assessment of concrete structures-research project MOSES. Beton-und Stahlbetonbau 108:630-640

31. Ferraris CF (2001) Concrete mixing methods and concrete mixers: state of the art. J Res Natl Inst Stand Technol 106:391-399. https://doi.org/10.6028/jres.106.016

32. Deutsches Institut für Normung e. V. (2012) DIN EN 12390-1:2012-12, Prüfung von Festbeton-Teil 1: Form, Maße und andere Anforderungen für Probekörper und 
Formen; Deutsche Fassung EN_12390-1:2012. Beuth Verlag $\mathrm{GmbH}$ : Berlin, Germany

33. Lang H, Fechter S (2017) Determining the modulus of elasticity of concrete with resonance analysis. BFT Int 2:188-195

34. Markert M, Birtel V, Garrecht H (2019) Influence of concrete humidity on the temperature development under fatigue compressive loading. IOP Conf Ser: Mater Sci Eng 615:012099. https://doi.org/10.1088/1757-899X/615/1/ 012099
35. Hümme J (2018) Ermüdungsverhalten von hochfestem Beton unter Wasser. Gottfried Wilhelm Leibniz Universität 36. Grübl P, Weigler H, Karl S (2002) Beton: Arten. John Wiley \& Sons, Herstellung und Eigenschaften

37. Hsu TTC (1981) Fatigue of plain concrete. In: Journal Proceedings. pp 292-305

Publisher's Note Springer Nature remains neutral with regard to jurisdictional claims in published maps and institutional affiliations. 